\title{
GLOBALIZAÇĀO E MUDANÇA DE IDENTIDADE ATRAVÉS DE ESTUDOS DE NARRATIVAS
}

Carlos Robles*

\section{Resumo}

Através de uma pesquisa qualitativa com dados e análise preliminares estudadas, o autor estuda os efeitos da globalizaçáo na mudança de identidade de participantes de um programa de intercâmbio de Ensino Médio realizado na Nova Zelândia durante seis meses. A metodologia de estudo de caso foi utilizada, com narrativas biográficas a partir de questionários e entrevistas realizadas na Nova Zelândia e no Brasil, em seu regresso, para verificar a mudança de identidade. O estudo ainda está em fase de análise dos dados coletados, mas com indícios suficientes para algumas conclusóes preliminares descritas neste artigo.

Palavras-chave: Globalização. Identidade. Escola. Currículo. Intercâmbio.

\section{EsTUdo DE CASO COMO METOdologia DE ESTUdo}

Muito utilizado em pesquisas linguísticas, sociológicas, psicológicas e educacionais, o estudo de caso é uma estratégia que possibilita a compreensão de fenômenos novos com base em teoria consistente através de temas observados (PUNCH, 1998; GALL; BORG, 2003; YIN, 2003).

O estudo de caso utiliza métodos de coleta de dados como questionários, entrevistas, gravaçóes em áudio e vídeo, narrativas biográficas, autobiográficas e, mais recentemente, a tecnologia disponível multimodal. De André (2015) analisa a investigação na educação da metodologia de caso etnográfico como "uma investigaçáo sistemática de situaçóes do cotidiano escolar".

Associado ao estudo de caso, seu estudo de forma etnográfica possibilita uma visão profunda do assunto estudado, mas também de forma ampla e conexa com um trabalho de campo de maior tempo, exigindo maior dedicação do pesquisador. Esse tipo de estrutura, critica a autora, apresenta dificuldades pela disponibilidade de tempo e recursos do pesquisador, nem sempre disponíveis.

\section{IDENTIDADE}

A inclusão social reflete uma identidade e, portanto, uma relação de poder. Silva (2000) afirma que, ao se fixarem padróes e normas de certa identidade, necessariamente existem processos que são definidos e cujas fronteiras de inclusão/exclusão são demarcadas.

Ao se diferenciar identidade, cria-se uma imposição cultural pela classe dominante. De acordo com Pacheco (2007, p. 3),

Mestre em Linguística Aplicada, doutorando em Estudos Linguísticos POSLIN/FALE, UFMG, pesquisa iniciada na Universidade de Auckland, Nova Zelândia, bolsista pela Fulbright e docente na Daytona State College, Estados Unidos.

Instrumento: R. Est. Pesq. Educ., Juiz de Fora, v. 19, n. 2, jul./dez. 2017 
a identidade não é "natural" nem inerente ao indivíduo, ela é preexistente a ele, e como a própria cultura se transforma, a identidade cultural do sujeito não é estática e permanente, mas fluida, móvel e, principalmente, não é uma imposição inocente, nem uma apropriação de todo inconsciente. A identidade cultural é por sua vez construída, manipulada e política.

A identidade cultural, portanto, mantém-se em um sistema fechado, restrito a um grupo social que se identifica com os costumes e hábitos tidos como padrão. Nesse contexto, a escola e seu currículo têm um papel importante não só na formação dessa identidade, mas também na sua permanência ao longo do tempo, transmitida às outras gerações.

No momento em que essa identidade está sujeita a fatores econômicos e à evolução tecnológica como internet, redes sociais, velocidade de informaçáo e influências de outras identidades culturais, dominantes ou não, no mesmo Estado ou num ambiente externo, ela então se encontra em mutação constante e, de acordo com Silva (2001), torna possível a universalização da cultura e das identidades e esse impacto global é mensurável pela influência da globalização nos grupos locais.

\section{Globalizaçấo e o currículo}

Norton (1997) conceitua identidade como a forma "como as pessoas percebem suas relaçóes com o mundo, como essas relaçóes são construídas através do tempo e espaço e como elas compreendem suas possibilidades no futuro". Aliado a esse conceito, podemos falar sobre os efeitos da globalização na construção de um novo currículo em seu sentido pleno, náo somente ao que se aprende na sala de aula (ELLIOTT, 1998).

Pacheco e Pereira (2007, p. 372) afirmam que "globalização e identidade são dois conceitos que, analisados no contexto das políticas educacionais e curriculares, não podem ser entendidos como se fossem dois extremos opostos e excludentes, mas como espaços posicionais e relacionais que são". Considerando o ambiente escolar como formador de uma identidade a partir de um currículo hegemônico, a globalização tem que ser discutida como um elemento que incorpora o conhecimento, seja ele padronizador ou formador de uma diversificação cultural. A globalização é um elemento, portanto, de autonomia e descentralização que entra em conflito com a padronização curricular das escolas. Uma crítica pode ser feita a seus efeitos, pois esse discurso existe mais na esfera política do que na prática de seus atores (professores e alunos).

\section{A investigaÇão narrativa}

Barkhuizen et alii (2014) citam Jerome Bruner como um dos fundadores da investigação narrativa em pesquisa qualitativa. Ele toma por base uma história como uma forma de organização de experiências, classificando-a em pragmática (associada ao pensamento racional) e narrativa (através da construção de histórias partindo de relatos, questionários, entrevistas e uma alternativa à pragmática, principalmente relacionada a pesquisas nas áreas de Educação, Linguística, Sociologia, Psicologia, entre outras).

Uma crítica ao pragmatismo é que ele falha na construção de uma experiência de vida e se volta para a forma acadêmica. A narrativa contém argumentos convincentes sobre a sua veracidade, mas também sobre o aspecto vivenciado dos fatos, portanto, é importante para ajudar a compreensão da natureza do ensino e a aquisição linguística no ambiente social e educacional.

Existem quatro razóes pelas quais a narrativa tem sido utilizada em recentes pesquisas, e não anteriormente: 1. Sua ampla utilização em pesquisa qualitativa. Os pesquisadores buscaram uma alternativa à pesquisa quantitativa e seu aspecto positivista, voltando para um aspecto mais humanista. 
2. A preocupação dos aspectos surgidos na pósmodernidade na busca de uma identidade cultural com a autoidentificação e individualidade.

3. A construção de identidades sociais na pósmodernidade que estáo constantemente mudando através da influência da globalização (HIROKI; HITO, 2014).

4. Por favorecer os grupos e indivíduos que não são assunto das pesquisas.

A narrativa une o narrador e a pesquisa através da utilização de histórias como dados para a pesquisa ou usando as estórias como ferramenta para análise dos dados e apresentação de conclusôes.

Clandinin e Conneley (2000) apresentam um processo descritivo para narrativa em pesquisa qualitativa. Eles definem a sequência narrativa como um produto de uma experiência reflexiva, indo da descrição (da experiência) para o julgamento (avaliação).

Uma distinção é feita por Polkinhorne (1995) entre "análise da narrativa”, na qual estórias são utilizadas como dados, e "análise narrativa", na qual histórias são utilizadas para análise de dados e apresentação de conclusóes. $\mathrm{O}$ autor exemplifica esses conceitos com a pesquisa de Gao (2010), Wette e Barkhruizen para análise da narrativa e a pesquisa de O'Mochain (2006) para a análise narrativa.

Outra distinção entre conceitos é de autobiografia e biografia. Essa distinção é feita através do papel do pesquisador interessado no relato de terceiros (biografia) ou dele próprio (autobiografia).

\section{NARRATIVAS UTILIZADAS EM PESQUISAS NA ÁREa de Linguística Aplicada}

No título "Narrative inquiry in language teaching", por Barkhuizen et alii, publicado em 2014, os autores apresentam um exemplo de duas narrativas curtas do livro de Peter Madgye (1994). Por meio de análise narrativa de duas histórias num contexto de ensino e aprendizado de inglês como língua estrangeira estudam as relaçóes de professores não nativos para avaliar seus desempenhos em relação a professores nativos. Colocam as relações entre elas para conclusões sobre professores de inglês não nativos em um contexto específico para chegar a algumas conclusôes, através de análise narrativa das duas estórias, em um contexto de ensino e aprendizado de inglês como língua estrangeira.

Através do estudo de 175 artigos que falam da importância da narrativa como metodologia, os autores agrupam-nas em cinco categorias:

- Memorias linguísticas: são relatos informais das experiências de aprendizado linguístico apresentados de forma não acadêmica. Elas são autobiografias e referem-se à análise narrativa.

- Estudo das memorias linguisticas: são análises feitas a partir de relatos informais e experiências linguísticas do pesquisador, sendo essas memórias utilizadas como dados.

- Estudo de caso autobiográfico: parecido com as memórias linguísticas, esse estudo de caso é escrito de forma acadêmica, incorporando tanto a análise narrativa (em que histórias são utilizadas como dados) como a análise de narrativa (em que histórias são utilizadas para análise de dados e apresentações de conclusões).

- Estudo de caso biográfico: trata-se do estudo de indivíduos no qual o pesquisador obtém dados do participante e os escreve de forma narrativa para sua análise.

- Estudo de narrativas múltiplas: é similar ao biográfico, sendo que a diferença é basicamente o número de participantes (entre dois e centenas).

\section{Características da investigaçáo NARRATIVA}

Por meio do exemplo acima, podemos citar as características da investigação ou pesquisa narrativa ao falaremos sobre cada uma delas. 
As narrativas podem ser faladas ou escritas. O pesquisador pode solicitar aos participantes que descrevam suas experiências através de um relato oral ou então pedir para que escrevam um texto sobre sua experiência em uma determinada situação a ser estudada.

São produzidas por pessoas que têm algo a dizer, mas não necessariamente construídas pelo participante. O pesquisador pode utilizar os dados de questionários e entrevistas para compor as narrativas em forma de história de vida do participante, narrada pelo pesquisador com fatos concretos extraídos das respostas obtidas.

Elas se desenvolvem ao longo do tempo. Uma história tem um começo, meio e fim de certa experiência estudada ao longo desse tempo, portanto, situando-se no tempo e espaço.

Têm estrutura coerente ao desenvolvimento descrito, seja pelo pesquisador ou pelo participante.

Kvale e Brinkmann (2009) definem sete estágios de narrativas: tematização, desenho, entrevista, transcrição, análise, verificação e comunicação dos resultados. A maioria dos estudos utilizando a investigação narrativa utiliza a entrevista acompanhada de outros métodos. Pesquisas em Linguística Aplicada, por exemplo, utilizam-se de entrevistas estruturadas ou semiestruturadas para compor narrativas.

Além de entrevistas, outros tipos de narrativas escritas são produzidos através de diários, histórias de aprendizado linguístico feitos por alunos e professores.

\section{ANÁlise da Narrativa}

Partindo-se do princípio de que a investigação narrativa é uma forma de pesquisa qualitativa, o pesquisador deve iniciar a análise da narrativa à medida que os dados forem sendo coletados. Dessa maneira, criase uma sistematização da análise dos dados coletados e permite uma estratégia mais ampla na continuidade da pesquisa através de novas coletas de dados.
Três conceitos são importantes na análise da narrativa, segundo Dönney (2007):

- Interativo - contrasta padróes ordenados e fazem idas e voltas entre dados coletados e sua análise. $\mathrm{O}$ término desse sistema se dá quando não aparecem novos elementos de dados coletados em sua análise.

- Emergente - implica um desenho de pesquisa em um amplo e aberto objetivo onde perguntas e respostas surgem a partir do estudo das narrativas.

- Interpretativo - é o produto da interpretação subjetiva dos dados da narrativa pelo pesquisador.

Polkinhorne (2007) distingue a análise de dados coletados por narrativas (como histórias produzidas diretamente pelo sujeito pesquisado) e não narrativas (dados em forma de entrevista, por exemplo).

A análise da narrativa se dá através do estudo de temas e de seu conteúdo, através da análise do discurso de uma estrutura e também através de histórias contadas que são analisadas em seu conteúdo.

Exemplos de análise temática estão nos estudos de Gao (2010), com narrativas autobiográficas de um aluno paraplégico chinês (SAKUI, 2002; COTTERALL, 2004 apud BARKHUIZEN, 2010). Esses estudos foram feitos em estudo de caso único.

Análises em estudos de casos múltiplos permitem a comparação de narrativas que apresentam temas em comum.

\section{Programa Ganhe o Mundo}

Criado pelo então governador do estado de Pernambuco Eduardo Campos, em 2011, o Programa Ganhe o Mundo considera a inclusão social e visa a uma grande mobilidade social. Os participantes desse projeto eram alunos de escolas públicas do estado de Pernambuco, de uma classe social classificada pelo IBGE como Classe D.

Sua justificativa, a aquisição linguística (no caso, inglês), era primordialmente para um desenvolvimento 
de novas habilidades e para melhoria das condiçóes de empregabilidade ou os colocarem em condições de maior competitividade com uma classe social dominante, que tem recursos para enviar seus filhos para um intercâmbio cultural, para pagar escolas privadas, entre outros privilégios.

Em seu estudo de caso, o autor investiga três grupos de participantes desse programa de intercâmbio patrocinado pelo Governo do Estado de Pernambuco que fizerem seis meses de Ensino Médio em escolas públicas em várias cidades na Nova Zelândia, vivendo com famílias hospedeiras neozelandesas por natureza ou cidadania adquirida nos anos de 2013, 2014 e 2015.

$\mathrm{O}$ objetivo dessa investigação é verificar se houve uma mudança de identidade a partir do desenvolvimento linguístico. Os participantes do Programa Ganhe o Mundo foram também selecionados pelo nível de L2 (nesse caso, inglês), além de terem aulas de inglês antes do embarque. Por essa razão, houve um desenvolvimento linguístico, em um ambiente multicultural proporcionado por um intercâmbio cultural, e desenvolvimento de um novo currículo.

Stenhouse (1975) afirma que "currículo é o que acontece às crianças na escola como o resultado do que o professor ensina. Isso inclui todas as experiências das crianças às quais a escola deve ser responsável”.

Com base nas relaçóes aluno/família neozelandesa; aluno/aluno (colegas novos e brasileiros que estavam na mesma cidade) e aluno/escola em seu novo ambiente, as narrativas evidenciam uma forma diferente de como o currículo é percebido pelos participantes em seu retorno ao Brasil, expressa por uma nova identidade.

O autor identifica seu estudo como estudo de caso etnográfico, apesar de algumas restrições em relação ao amplo estudo etnográfico.

O estudo etnográfico "pleno" é definido por Sato e Souza (2001) como "uma pesquisa sobre e nas instituiçóes baseada na observação participante e/ou nos registros permanentes da vida diária nos locais e contextos em que ela naturalmente acontece".

Os registros obtidos pelo autor foram feitos a partir de relatos em questionários e entrevistas semiestruturadas na Nova Zelândia e Pernambuco, nos locais onde os participantes residiram $\mathrm{e}$ permanentemente residem no Brasil sem a observação permanente desses ambientes. As observações foram parciais em ambos os locais durante um período de tempo condensado, porém captando pontos de vistas de diferentes grupos relacionados ao caso sob investigação (WALKER, 1980). O autor também registrou, ao longo de suas visitas, tanto na Nova Zelândia quanto em Pernambuco, imagens e vídeos dos participantes durante o programa e no seu retorno.

Nesse sentido, o Programa Ganhe o Mundo transporta esses participantes para outra realidade, e isso pode ser observado já a meio caminho entre Pernambuco e Nova Zelândia, através da afirmação de um dos participantes entrevistados em trânsito no aeroporto de Dubai, nos Emirados Árabes:

... O aeroporto (Dubai) é enorme! A gente se perde dentro! Me chamou a atenção as pessoas vestidas diferente, com rosto tampado, da mesma cor. Muitas luzes, muito dourado, tinha até uma Ferrari para vender.

Essa é uma primeira consciência de outra identidade cultural expressa pela sua forma. As cores (mesma cor; dourado); grandiosidade (é enorme! A gente se perde dentro); vestuário diferente (vestidas diferente, com o rosto tampado). Esses são os primeiros sinais de grandes mudanças, da consciência de outra identidade com um deslocamento de apenas horas entre um continente e outro.

O Programa Ganhe o Mundo não foi idealizado para uma mudança curricular. $\mathrm{O}$ Brasil não tem um currículo padrão no que diz respeito ao Ensino Médio hoje, mas muitas discussóes e progressos estão sendo 
feitos para sua possível melhoria. Paulo Freire (1996, p. 127) afirma que "o discurso da globalização que fala da ética esconde, porém, que a sua é a ética do mercado, e não a ética universal do ser humano pela qual devemos lutar bravamente se optarmos, na verdade, por um mundo de gente”. A padronização curricular, que apresenta um espaço de aquisição de conhecimentos homogêneo, ao ser influenciada pela globalização através da velocidade dos meios de comunicação disseminadores de diversidades de cultura e identidade, contrapóe-se à questão do global x local.

A globalização muda conceitos, reforma valores, muda hábitos, formando novas identidades ao nível supranacional, reforça a mudança dos conceitos nacionais, agrega-os aos existentes, de âmbito pessoal, profissional e revê as relações e valores da outra identidade. Não se faz julgamento aqui se essa nova identidade é melhor ou pior que a outra. Apenas reconhece que a globalização é um fator modificador da identidade existente.

Nesse âmbito, a experiência curricular e as relaçôes examinadas na pesquisa do autor através de narrativas biográficas evidencia que houve mudança de identidade, adquirida em outro ambiente externo que o da fronteira inicial dos participantes, no caso, vivendo seis meses na Nova Zelândia em contato com as famílias que os acolheram, ambiente escolar e as novas relaçóes multiculturais, pois não somente os participantes interagem com a cultura branca neozelandesa, mas também com a cultura maori e com famílias que adquiriram a nacionalidade neozelandesa, mas que imigraram de outros países asiáticos e das ilhas na Polinésia.

\section{Narrativas BIOGRÁfiCAS}

Em sua pesquisa, o autor apresenta narrativas biográficas coletadas a partir de questionários e entrevistas que estão, no momento, sendo analisadas. Através do estudo comparativo de nove narrativas, o autor conclui que houve temas recorrentes que dão indícios para afirmar que houve uma mudança de identidade incorporada à existente ou modificada.

A seguir, temos exemplos de possíveis mudanças de identidade a partir da análise preliminar dessas narrativas.

\section{Carolina}

Carolina é da cidade de Olinda, no estado de Pernambuco. Com uma população de aproximadamente 390 mil habitantes, Olinda situa-se ao lado da capital do estado, Recife, e é uma cidade patrimônio mundial da humanidade declarada pela UNESCO com um acervo barroco do colonial português.

\section{Sua escola no Brasil}

Carolina morava com os pais e estudava em uma escola pública na cidade. Ela considera sua escola no Brasil grande, com aproximadamente 500 estudantes. Sua escola mudou gradativamente de meio período para período integral. No início, somente três vezes por semana havia somente um período de $7 \mathrm{~h} 30$ às $17 \mathrm{~h}, \mathrm{o}$ resto da semana era somente meio período, isto é, de $7 \mathrm{~h} 30$ às $13 \mathrm{~h}$. A escola fez parte do projeto do governo do estado para se tornar uma "escola integrada".

\section{Sua ResidênCIa na Nova Zelândia}

Ela foi colocada em uma residência e a primeira pessoa que ela encontrou no aeroporto de Auckland foi alguém da escola, que a levou para seu novo lar na Nova Zelândia.

Sua primeira impressão sobre o novo lar foi boa. Ela disse: "eu olhei em volta e gostei de tudo". Seu quarto era confortável, realmente grande, e seus pais anfitrióes eram gentis e pacientes com ela, ajudando-a a compreender seu inglês. Ela pensou como seria fácil se adaptar a esse novo país, cultura e lar. Ela estava muito à vontade com os pais anfitrióes e se sentiu segura em expressar o que gostava ou não sobre qualquer assunto. 
Ela disse que havia mais espaço no seu quarto na Nova Zelândia, mas que os móveis não eram diferentes de seu próprio quarto no Brasil. Tinha uma cama, uma escrivaninha com um computador, basicamente a mesma coisa, exceto pelo tamanho: era muito maior na Nova Zelândia. Tinha também essa enorme janela com vista para o jardim, coisa que não tinha no Brasil.

Havia outras diferenças na casa: a casa toda era acarpetada. Ela nunca tirou os sapatos porque os pais anfitriōes não falaram que ela deveria tirá-los...

\section{Hábitos ALIMENTARES}

"Os hábitos alimentares deles também eram muito diferentes. No Brasil, a gente só toma café com leite e pão. Na Nova Zelândia, eu comia cereal, torrada com geleia e leite ou chá."

Ela concluiu que o almoço não era tâo importante na Nova Zelândia pela quantidade de comida que comia, era somente um sanduíche, fruta, nada pesado se comparado com o almoço no Brasil, com arroz, feijão, carne e salada. Aquilo que era o jantar para a família neozelandesa era o almoço para a família brasileira. $\mathrm{O}$ almoço é a refeição principal dos brasileiros.

Ela descreve o jantar como muito cultural e "sagrado" na Nova Zelândia. A família se senta junto e conversa. Tem muitos vegetais. Ela não comia vegetais no Brasil e teve que começar a gostar e comê-los. Ela começou a comer brócolis, cenoura, ervilha e milho. Ela também começou a apreciar peixe e batatas na Nova Zelândia, algo que não havia no Brasil. De todos os vegetais que ela comia na Nova Zelândia, somente milho cozido foi o que continuou comendo no Brasil.

\section{EXPERIÊNCIA ESCOLAR Na Nova ZelâNDIA}

Carolina disse que sua experiência na sala era diferente do Brasil. No Brasil, ela tinha que estudar quatorze matérias obrigatoriamente. Não passar em uma delas faria repetir o ano todo, incluindo as outras que ela tinha passado. Na Nova Zelândia, ela escolheu somente seis matérias. Ela escolheu matemática, biologia, inglês, trabalhos em madeira, esportes e espanhol. Ela disse que tinha muita prática em todas as matérias e também excursóes, algo que raramente tinha no Brasil.

Outra diferença entre a escola na Nova Zelândia e no Brasil, além do tamanho, era como eram equipadas. $\mathrm{Na}$ Nova Zelândia, havia computadores, laboratórios e não somente teoria. Os professores mostravam o lado prático das matérias ensinadas e os alunos podiam ver como a prática contribuía para um aprendizado que faz sentido e é mais fácil de memorizar.

\section{REFLEXóES}

Carolina seguiu a vida na Nova Zelândia apreciando as mudanças de estaçóes, do verão para o outono, passou a Páscoa com a família hospedeira e se adaptou aos aspectos culturais da vida cotidiana na Nova Zelândia. Em junho de 2013, ela estava a quatro semanas de seu retorno ao Brasil.

Nesse momento, ela começou a refletir sobre retomar a vida no Brasil. Ela informou que aprendeu tantas coisas novas que gostaria de usar esse conhecimento adquirido sobre a cultura da Nova Zelândia e estilo de vida. Ela pensou como seria diferente no seu próprio país com a experiência adquirida. Ela também queria que as pessoas à sua volta aprendessem sobre a Nova Zelândia e como sua cultura e pessoas são maravilhosas.

Naquele momento, ela pensou que o aspecto mais difícil em sua volta ao Brasil seria dizer adeus à sua família hospedeira e aos amigos na escola. Ela disse que sentiria saudades de cada momento que ela viveu no exterior com amigos e família, mas que não falaria naquilo. Ela queria terminar sua experiência de uma forma sem desespero.

\section{DiferenÇAS Na VOLTA Ao Brasil}

Ela enfatizou que a coisa mais impressionante era o tamanho das casas na Nova Zelândia comparadas às do Brasil. Havia água quente no chuveiro, "essencial no frio da Nova Zelândia”, e aquecimento central. 
Ela costumava ajudar a tirar a mesa depois do jantar e lavar os pratos usando água quente, algo que ela aprendeu lá.

Na Nova Zelândia, as pessoas reciclam o lixo, no Brasil, não. Ninguém joga nada na rua, lixo nas calçadas. Ela nunca viu ninguém jogando lixo e tinha um sentimento estranho quando via alguém muito perto dela fazendo isso no Brasil. Ela começou a falar para eles não fazerem isso.

A relação de Carolina com seus pais e tia era muito boa. Ela voltou à sua rotina no Brasil e voltou para a escola para terminar o Ensino Médio no final do ano e estudou para o vestibular. Ela tinha uma melhor noção de que campo estudar na universidade.

Ela estava pensando em estudar relações públicas na universidade. Ela pensava nisso havia muito tempo, mas não tinha certeza. Quando ela voltou da Nova Zelândia, ela estava segura disso. $\mathrm{O}$ seu intercâmbio no exterior deu essa certeza...

Em sua volta, sua percepção do Brasil foi a de um país que necessitava de melhorias. Ela adquiriu o hábito de dizer "obrigado", "desculpe", "com licença” e usar outras expressôes de polidez. Não foi somente o fato de os amigos não usarem essas expressóes que a fez pensar dessa maneira, mas também o fato de eles acharem que ela exagerava. Ela acha que mudar simples hábitos assim seria um bom começo para melhorar as coisas no Brasil.

Seus pais acharam que ela voltou mais madura e independente, com maior confiança e, portanto, relaxaram um pouco as regras com ela. Eles a deixam sair mais e confiam que ela vai fazer as coisas certas, sem ter maiores problemas.

\section{Conclusão: MUdANÇA DE IDENTIDAdE COM ESSA EXPERIÊNCIA}

Essa narrativa evidencia a aquisição de uma nova identidade adquirida a partir de uma experiência de convivência com outra, em um estado diferente, em contraste com aquela que ela trouxe consigo, propiciada por um programa social de intercâmbio cujo meio foi o desenvolvimento adquirido de uma língua estrangeira (no caso, inglês).

Em sua pesquisa, o autor está analisando os dados para poder verificar a aquisição de um novo currículo, no sentido amplo estudado por Elliott (1998), isto é, visando não somente ao que se ensina dentro da sala de aula, mas ao que seria uma fusão do currículo do Brasil e o da Nova Zelândia, que está sendo conceituado pelo autor de "Terceiro Currículo", produto dessa mudança de identidade a partir do Programa Ganhe o Mundo.

\section{GLOBALIZATION AND IDENTITY CHANGES THROUGH NARRATIVE ANALYSIS}

\section{Abstract}

Through a qualitative research inquiry with preliminary data analysis studied, the author researches about the effects of globalization on identity changes with participants of a secondary exchange program to New Zealand for six months. Case study methodology was used with biographic narratives from questionnaires and interviews in New Zealand and Brazil on their return to verify this identity change. The research is still in progress to analyze the collected data but with strong evidence of some preliminary conclusions described in this article.

Keywords: Globalization. Identity. School. Curriculum. Exchange. 


\section{GLOBALIZACIÓN Y CAMBIOS DE IDENTI- DAD POR MEDIO DE UNA INVESTIGACIÓN CUALITATIVA Y PERCEPTIVA}

\section{Resumen}

Por medio de una investigación cualitativa y perceptiva, el autor investiga acerca de los efectos de la globalización en los cambios en la identidad cultural entre los participantes de un programa de intercambio de secundaria, de una duración de seis meses, en Nueva Zelanda. La metodología utilizada es la de estudios de casos a través de narrativas biográficas, y de elaboración de cuestionarios y entrevistas personales en Nueva Zelanda y Brasil. Estas entrevistas son elaboradas a su regreso para verificar posibles cambios de dicha identidad cultural. Esa investigación, todavía en curso, y en proceso de análisis de los datos colectados, nos permite afirmar, no obstante, que hay fuertes evidencias de que algunas de las conclusiones preliminares abordadas en ese artículo confirman nuestra tesis de partida, los fuertes cambios en la identidad cultural referida.

Palavras clave: Globalización. Identidad. Escuela. Currículo. Intercambio.

\section{REFERÊNCIAS}

BARKHUIZEN, G.; BENSON, P.; CHIK, A. Narrative inquiry language teaching and learning research. New York: Routledge, 2014.

CLANDININ, D. J.; CONNELLY, F. M. Narrative inquiry: experience and story in qualitative research. San Francisco: Jossey-Bass, 2000.

COTTERALL, S. It's just rules... that's all it is at this stage. In: BENSON, P.; NUNEN, D. (Ed.): Learners'stories: difference, diversity in language learning. Cambridge: Cambridge University Press, 2004, pp. 101-18.

DE ANDRÉ, M. E. D. A. Etnografia da prática escolar. Prática pedagógica. Campinas: Papirus, 2015.

DÖRNYEI, Z. Research methods in applied linguistics: quantitative, qualitative and mixed methodologies. Oxford: Oxford University Press, 2007.

ELLIOTT, J. The curriculum experiment - meeting the challenge of social change. Open University Press, 1998.

FREIRE, P. Pedagogia da autonomia: saberes necessários à prática docente. São Paulo: Paz e Terra, 1996, p. 27.

GALL, M. D.; GALL, J. P.; BORG, W. T. Educational research (7. ed.). White Plains: Pearson Education, 2003.

GAO, X. Autonomous language learing against all odds. System, 2010.

HIROKI, I.; HIRO, S. Cosmopolitanism as cultural capital: exploring the intersection of globalization and stratification. Edinburgh: Sage Publications, Inc, 2014.

KVALE, S.; BRINKMANN, S. InterViews: learning the craft of qualitative research interviewing. 2. ed. Los Angeles: Sage, 2009.

MEDGYES, P. The non-native teacher. London: MacMillan, 1994.

NORTON, B. Language, identity and the ownership of English. TESOL Quarterly, 31(3), pp. 409-429, 1997. Disponível em: $<$ http://dx.doi.org/10.2307/3587831>. Acesso em 29 nov. 2016.

O'MOCHAIN, R. Discussing gender ad sexuality in a context-appropriate way: queer narratives in EFL college classroom in Japan. Journal of Language Identity and Education. v. 5, p. 51-56, 2006.

PACHECO, J. Identidade cultural e alteridade: problematizaçóes necessárias. In: Revista eletrônica dos discentes de História. Santa Cruz do Sul: UNISIC - Spartacus, 2007.

PACHECO, J. A.; PEREIRA, N. Globalização e identidade no contexto da escola e do currículo. Cadernos de Pesquisa, v. 37, n.131, p. 3, maio/ago. 2007. Braga: Universidade do Minho. 
POLKINGHORNE, D. E. Validity Issues in Narrative Research. Qualitative Inquiry, v. 13, n. 4, p. 471-486, 2007.

PUNCH, K. Introduction to social research: quantitative and qualitative approaches. Thousand Oaks: Sage, 1998.

ROBLES, C. The Third Curriculum - Win the World Program - Pernambuco, Brazil. Revista Linguagem e Ensino, v. 19, n. 1. Universidade Católica de Pelotas, 2016.

SILVA, M. Novas tecnologias: educação e sociedade na era da informaçáo. Belo Horizonte: Autêntica, 2001.

SILVA, T. (Org.). Identidade e diferença: a perspectiva de estudos culturais. Petrópolis: Vozes, 2000.

STENHOUSE, L. An introduction to curriculum research development. London: Heinemann, 1975.

WALKER, R. The conduct of educational case study: ethics, theory and procedures. In: DOCKRELL, W. B.; HAMILTON, D. Rethinking educational research. London: Hodder and Stonghton, 1980.

WETTE, R. and BARKHUIZEN, G. Teaching the book and educating the person: challenges for university English language teachers in China. Asia Pacific Journal of Education. v. 29, p. 195-212, 2009.

YIN, R. Case study research. Design and methods. 3. ed. Thousand Oaks: Sage, 2003.

Enviado em 14 de dezembro de 2016. Aprovado em 19 de junho de 2017. 